\section{TEORIA DA CEGUEIRA DELIBERADA E SUA APLICABILIDADE NO ORDENAMENTO JURÍDICO BRASILEIRO EM CRIMES DE LAVAGEM DE CAPITAIS}

$\begin{array}{lcccr}\text { DELIBERATED } & \text { BLINDNESS } & \text { THEORY } & \text { AND } & \text { ITS } \\ \text { APPLICABILITY } & \text { TO MONEY } & \text { LAUNDERING } & \text { CRIME } & \text { IN } \\ \text { BRAZILIAN LEGAL SYSTEM } & & & \end{array}$

Mykael Nascimento Gonçalves ${ }^{1}$

Italo Schelive Correia ${ }^{2}$

\title{
RESUMO
}

Considerando a crescente utilização da Teoria da Cegueira Deliberada em casos de grande repercussão social em âmbito nacional, torna imprescindível o estudo e entendimento sobre a mesma, objetivou-se identificar como essa teoria tem impactado em crimes de lavagem de capitais, os limites a que a Teoria da Evitação da Consciência está subordinada e quais os requisitos da sua aplicabilidade. Para tanto, procedeu-se ao método da pesquisa bibliográfica no direito comparado, para análise do conceito e evolução histórica da teoria, como também estudo dos pontos referentes à Teoria da Cegueira Deliberada no ordenamento jurídico brasileiro, tanto na jurisprudência como na doutrina. Desse modo, observou-se que adoção da Teoria da Cegueira Deliberada no ordenamento jurídico brasileiro possui efeito positivo no combate a crimes de lavagem de capitais o que permite concluir que, desde que respeitado os seus requisitos a teoria não encontra obstáculo suficiente para impedir a sua aplicação.

PALAVRAS-CHAVE: Cegueira Deliberada; Direito Penal; Lavagem de Capitais.

\section{ABSTRACT}

Considering the growing use of the Theory of Deliberate Blindness in cases of great social repercussion at the national level, it is essential to study and understand it, it aims not only to identify how this theory has impacted on money laundering crimes, but also what are the limits to which the Theory of Avoidance of Consciousness is

\footnotetext{
${ }^{1}$ Graduando em Direito pela Univesidade Estadual do Tocantins (Unitins), Câmpus Dianópolis/TO. Email mykaelm3@gmail.com ORCID https://orcid.org/0000-0003-3005-7035

2 Doutorando em Desenvolvimento Regional - UFT, Mestre em Geografia - UFT, Professor do curso de Direito da Universidade Estadual do Tocantins (UNITINS), Câmpus Dianópolis, E-mail: italo.sc@unitins.br, ORCID ID: 0000-0002-7858-4531.
} 
subordinated and what are the requirements of its applicability. To this end, the method of bibliographic research in comparative law is used to analyze the concept and historical evolution of the theory, as well as to study the points related to the theory of deliberate blindness in the Brazilian legal system, both in jurisprudence and in doctrine. Thus, it is observed that the adoption of the theory of deliberate blindness in the Brazilian legal system has a positive effect on the fight against money laundering crimes, which allows us to conclude that, as long as its requirements are met, the theory does not encounter sufficient obstacles to prevent its application being an important milestone in Brazilian criminal law and criminal procedure.

KEYWORDS: Criminal law; Money laundering; Willful blindness.

\section{INTRODUÇÃO}

A Teoria da Cegueira Deliberada refere-se a uma construção doutrinária, com origem no common law, que tem a proposta de penalizar sujeitos que possuindo condições para perceber certa situação de ilicitude ignora intencionalmente com a intenção de conseguir vantagem. Historicamente a teoria teve seu primeiro registro de aplicabilidade na Inglaterra, no ano de 1861, no caso conhecido como Regina vs. Sleep.

O estudo desta teoria mostra-se relevante pela eficácia no combate aos crimes de lavagem de capitais e suas espécies, sendo importada para o ordenamento jurídico Brasileiro em processos emblemáticos. A utilização da teoria no Brasil não é pacífica, havendo divergências de entendimento tanto na doutrina como na jurisprudência. Diante disto o presente trabalho tem por objetivo analisar se a teoria da cegueira deliberada é passível de aplicação no direito pátrio, bem como definir seus limites e contornos.

Através da metodologia de pesquisa bibliográfica foi realizado um estudo no direto comparado, sobre o conceito da Teoria, como é definida, onde se deu a sua origem e como foi sua evolução no decorrer da história.

Posteriormente, abordou-se a Teoria do dolo no Brasil, analisando qual a definição, as tendências e espécies de dolo no ordenamento jurídico brasileiro, tendo o cuidado de evidenciar a diferença entre dolo direto e dolo eventual. Sem tal 
análise do instituto do dolo no ordenamento jurídico pátrio, a compreensão da Teoria ficaria comprometida.

A partir de então, tornou-se viável examinar se é possível adotar a teoria da ignorância deliberada no âmbito do direito nacional, sendo analisado casos emblemáticos da aplicação da teoria no Brasil.

Começando pelo primeiro caso de incidência no país, o Furto ao Banco Central, em seguida analisou-se a teoria da cegueira deliberada utilizada na Operação Lava Jato, como também na Ação Penal n 470 conhecida como mensalão.

Por fim, tratou-se, das divergências, requisitos e cautelas necessárias acerca da importação da Teoria da Cegueira Deliberada, para verificar a aplicação da teoria no Brasil.

\section{TEORIA DA CEGUEIRA DELIBERADA}

A Teoria da Cegueira Deliberada (willful blindness), também conhecida como Instrução do Avestruz (Ostrich Instruction) ou ainda teoria da Evitação da Consciência (conscious avoidance doctrine), refere-se a uma construção doutrinária para oferecer resposta jurídica para os casos em que o agente possuindo condições para perceber certa situação de ilicitude ignora intencionalmente com fim de alcançar vantagem. Beck (2011, p. 49) traduz a doutrina dizendo que:

A doutrina justifica a responsabilização criminal nos casos em que o indivíduo se coloca deliberadamente em uma situação de desconhecimento acerca do fato, já antecipadamente visando a furtar-se de eventuais consequências futuras da sua conduta na esfera penal.

Essa teoria, equipara a ignorância intencional ao efetivo conhecimento acerca da realidade tem como objetivo levar punição para o agente que, voluntariamente, se coloca em situação de ignorância sobre algum fato penalmente relevante, visando se beneficiar e se livrar de eventual responsabilidade.

A escolha do nome "instrução da avestruz", está relacionado com o fato de o agente ter comportamento semelhante ao do animal, que enterra a sua cabeça quando se encontra em situação de perigo, de igual modo o agente "esconde a 
cabeça" para não tomar conhecimento da natureza ou extensão do seu ilícito praticado. Luban (1999, p. 968), explica que avestruz seria um "débil moral que nega a si mesmo o fato de que enfrenta um dilema de natureza também moral, no qual sua atitude parece menos grave que a atuação com conhecimentos certos sobre os dados relevantes de sua própria conduta".

Segundo Cabral (2012, p. 11):

\begin{abstract}
Essa doutrina foi criada para as situações em que um agente finge não enxergar a ilicitude da procedência de bens, direitos e valores com o intuito de auferir vantagens. Dessa forma, o agente comporta-se como um avestruz, que enterra sua cabeça na terra para não tomar conhecimento da natureza ou extensão do seu ilícito praticado.
\end{abstract}

Ou ainda nas palavras de Martins (2014, p. 137): "A doutrina funda-se na responsabilização do agente, que, podendo aprofundar seu conhecimento sobre determinados fatos, prefere manter-se "cego" - daí a nomenclatura - diante daquilo que poderá prejudica-lo."

Historicamente é originária da Common Law, tendo o primeiro registro de aplicabilidade da teoria na Inglaterra, no ano de 1861, no caso conhecido como Regina vs. Sleep (ROBBINS, 1990).

No caso em tela Sleep foi investigado e processado por ter colocado em embarcação mercantil barris com parafusos de cobre, alguns dos parafusos eram de propriedade do Estado e era este fato de fácil presunção pois estavam assinalados em forma de flecha, sinal típico desses parafusos estatais.

Por esses fatos o júri de primeira instância considerou o autor culpado, o condenando por delito de má administração de bens públicos.

O agente recorreu da decisão sob alegação de não possuir conhecimento de que os parafusos eram de propriedade estatal, em segunda instância teve sua condenação revogada, por não ter sido provado que o senhor Sleep se absteve propositadamente de tomar conhecimento de que se tratava de bem estatal (ROBBINS, 1990).

Com base nesta decisão conclui-se que, caso estivesse comprovado a intenção do agente em deliberadamente ignorar fato penalmente relevante, receberia reposta punitiva do Estado correspondente aos casos de pleno 
conhecimento. Após esse fato, essa alternativa jurídica passou a ser abundantemente empregada nos tribunais ingleses.

A Suprema Corte dos Estados Unidos no ano de 1899 aplicou pela primeira vez a Teoria da Cegueira Deliberada no caso Spurr vs. United States ao decorrer dos anos a doutrina alavancou no direito Estadunidense e foi amplamente utilizada em crimes de lavagem de dinheiro e tráfico de drogas (BECK, 2011).

De acordo com Sergio Moro (2007, p. 95) a "willful blindness doctrine" tem sido recepcionada pelos tribunais norte-americanos quando há prova de que o agente tinha conhecimento da expressiva probabilidade de que os bens, direitos ou valores envolvidos eram provenientes de crime; e que o agente agiu de modo indiferente a esse conhecimento. A respeito da aplicação da teoria no direito norteamericano em relação ao crime de lavagem de dinheiro, Moro (2010, p. 63), faz ainda considerações:
A lei norte-americana não explícita quanto à admissão ou não do dolo eventual no crime de lavagem de dinheiro. Não obstante, por construção jurisprudencial, tal figura vem sendo admitida nos tribunais norte- americanos por meio da assim denominada willful blindness ou conscious avoidance doctrine, literalmente, a doutrina da "cegueira deliberada" e de "evitar a consciencia".

A Teoria da Cegueira Deliberada também ganhou espaço no âmbito do Civil Law através do direito espanhol, sendo conhecida como evitação de consciência "ignorância deliberada", passando a ser aplicada em situações em que o desconhecimento provocado faz supor o dolo em crimes de tráfico de drogas, contra a saúde pública e crimes econômicos (MARTINS, 2014).

A primeira vez que a referida teoria foi apreciada, foi em decisão do Tribunal Supremo Espanhol, no qual julgou uma receptação praticada por um indivíduo que transportava grande quantia de dinheiro oriundo do tráfico de drogas e que argumentou o desconhecimento da origem ilícita (VALLES, 2007).

Desta forma, extrai-se tanto de decisões que se tronaram históricas de tribunais dos países citados, quanto da mais renomada doutrina, que aquele que mesmo não possuindo pleno conhecimento do fato, percebe a probabilidade de conduta ilícita se coloca em situação de ignorância intencional deve ser responsabilizado. 


\section{ANÁLISE DO DOLO NO DIREITO PENAL BRASILEIRO}

Com a finalidade de tornar possível a análise da aplicação da Teoria da Cegueira Deliberada no Direito Penal brasileiro, é primordial que sejam feitas considerações acerca dos institutos do dolo direto e do dolo eventual, especialmente no âmbito do ordenamento jurídico pátrio.

Após examinar os preceitos previstos no nosso sistema legal, assim como verificar o entendimento doutrinário acerca desses mandamentos legais, será possível examinar se é possível a adoção da teoria da cegueira deliberada no Direito brasileiro, bem como quais são os seus termos e limites.

Vale a pena mencionar que existem divergências conceituais nas teorias que buscam explicar o dolo, no entanto, será objeto de análise apenas o finalismo de Hans Welzel que foi a teoria adotada como base para conceituar o dolo no Brasil.

\subsection{Teoria do Dolo no Brasil}

O dolo no Direito Penal brasileiro é idealizado, segundo a doutrina majoritária brasileira, pela Teoria Finalista de Hans Welzel. Na lição de Welzel (1970, p. 277) é admitia a existência de somente dois elementos do dolo: consciência e vontade. Conforme o escritor, "dolo, em sentido técnico penal, é somente a vontade de ação orientada à realização do tipo de um delito", isto é, "a vontade que tem um agente de praticar um ato, previsto como crime, consciente da relação de causalidade entre a ação e o resultado"

Conforme Bitencourt (2018, p. 521):

Dolo é a consciência e a vontade de realização da conduta descrita em um tipo penal", leciona ainda que, "o dolo, puramente natural, constitui o elemento central do injusto pessoal da ação, representado pela vontade consciente da ação dirigida imediatamente contra o mandamento normativo.

Na mesma vertente assinala Juarez Cirino dos Santos (2005, p. 62):

O dolo, conforme um conceito generalizado, é a vontade consciente de realizar um crime, ou, mais tecnicamente, vontade consciente de realizar o tipo objetivo de um crime, também definível como saber e querer em relação às circunstâncias de fato do tipo legal. 
De acordo com Cunha (2016, p. 193), o dolo é a vontade consciente dirigida a realizar, ou aceitar realizar, a conduta prevista no tipo penal incriminador.

Verifica-se, portanto, que na doutrina pátria, é pacífico o entendimento de que o dolo é o que se pode denominar de elemento subjetivo do tipo penal, que se traduz no proposito, espontâneo e consciente, de praticar o crime, ou de se assumir o risco que será produzido pela conduta

Com a adoção do finalismo o dolo foi migrado da culpabilidade para o fato típico, de modo que a denominada "consciência da ilicitude da conduta" deixou de ser analisada dentro do dolo em si e passou a fazer parte do elemento da culpabilidade.

Consequentemente, se o fato concebe uma conduta dolosa não é preciso verificar se $o$ agente tinha consciência de que sua conduta era contrária ao direito, que somente será averiguada na culpabilidade.

Segundo Cunha (2016, p. 183):

\begin{abstract}
Ao migrar para o fato típico, o dolo passa a ter dois elementos: consciência e vontade. O tipo, por sua vez, passa a ter duas dimensões: a dimensão objetiva (conduta, resultado, nexo e adequação típica) e a dimensão subjetiva, representada pelo dolo ou pela culpa. Ao se destacar da consciência da ilicitude, alocada como elemento próprio na culpabilidade, o dolo perde o seu elemento normativo. Por este motivo é que, no finalismo, o dolo é natural (despido de valoração), é o dolus bonus. Contrapõe-se, portanto, à perspectiva causalista do dolo normativo, do dolus malus.
\end{abstract}

\title{
3.2 Espécies de Dolo
}

A redação do artigo 18 do Código Penal ministra que o crime é doloso quando o agente quis o resultado ou assumiu o risco de produzi-lo. Verifica-se, portanto, que o Direto Penal brasileiro aderiu de maneira expressa a teoria da vontade em relação ao dolo direto e a teoria do consentimento para o dolo eventual.

\subsection{Dolo Direto}

Segundo a teoria da vontade ocorre o dolo direto quando existe a consciência de que a conduta pode lesar um bem jurídico, cominado com a vontade de que este bem jurídico seja lesionado. 
Teles (2006), assinala que a teoria da vontade, teoria clássica elaborada por Carrara (2002), define o dolo como a intenção praticamente perfeita de intentar uma ação que se concebe contrária à lei. Isto é, quem tem como intento a prática de um fato definido em lei como crime, atua com dolo.

Bitencourt (2018, p. 527) define que o dolo direto ocorre quando o "agente quer o resultado representado como fim de sua ação", sendo que "a vontade do agente é dirigida à realização do fato típico".

Assinala Bitencourt (2018, p. 528), que o dolo direto se divide em três aspectos:

1) a representação do resultado, dos meios necessários e das consequências secundárias; 2) o querer a ação, o resultado, bem como os meios escolhidos para a sua consecução; 3) 0 anuir na realização das consequências previstas como certas, necessárias ou possíveis, decorrentes do uso dos meios escolhidos para atingir o fim proposto ou da forma de utilização desses meios.

\subsection{Dolo Eventual}

Já a teoria do consentimento prevê que há dolo eventual quando o agente tem consciência de que a conduta pode gerar um resultado criminoso e prossegue na prática, assumindo o risco de produzir o resultado delituoso

Prado (2011, p. 340) dispõe que, no dolo eventual "o autor considera seriamente como possível a realização do tipo legal e se conforma com ela...o agente consente ou se conforma, se resigna, ou simplesmente assume a realização do tipo penal".

Discorre de maneira semelhante Roxin (2007, p. 201), ao afirmar que "agir com dolo eventual aquele que, suspeitando da presença dos elementos do tipo objetivo, mas sem a certeza absoluta, age de modo a possivelmente produzir o resultado típico".

Bitencourt (2018, p. 532) em sua obra traz a distinção do dolo direto para o dolo eventual, assinalando que: "o primeiro é a vontade por causa do resultado; o segundo é a vontade apesar do resultado".

Averiguado, portanto, o conceito, origem e requisitos da chamada teoria da Cegueira Deliberada, de igual modo, feito análise suscita das tendências sobre o 
dolo no Direito Penal brasileiro, passa-se à efetiva avaliação sobre a harmonia entre a teoria Evitação da Consciência e o Ordenamento jurídico brasileiro.

\section{REPRODUÇÃo DA TEORIA DA CEGUEIRA DELIBERADA EM PROCESSOS BRASILEIROS}

Tendo feito as observações pertinentes sobre a teoria da Cegueira Deliberada em relação ao direito comparado e o dolo no direito penal brasileiro torna-se viável examinar se é possível a adoção da teoria da ignorância deliberada no âmbito do direito pátrio, bem como quais são os seus termos e limites.

Será apresentado, alguns cenários em que a doutrina da Evitação da Consciência foi aplicada no Brasil, com o propósito de discorrer sobre os fundamentos adotados pelos Juízos que aplicaram a referida teoria, bem como em quais crimes ocorreram a sua aplicação.

\subsection{Furto ao Banco Central}

$\mathrm{Na}$ busca em promover uma tutela penal eficiente a teoria foi sendo inserida no ordenamento jurídico brasileiro e ganhou evidência por meio de casos emblemáticos, como no famoso caso do furto ao Banco Central em Fortaleza, sendo esse um dos primeiros episódios de aplicação da teoria no âmbito jurídico brasileiro.

$\mathrm{Na}$ ocasião, uma quadrilha, que havia alugado uma casa a 80 metros de distância da instituição financeira, durante três meses cavou um túnel que deu acesso Banco central. Entre os dias 5 e 6 de agosto do ano de 2005 (entre sextafeira e sábado), a quadrilha teve acesso ao cofre e conseguiu furtar mais de 164 milhões de reais, em cédulas de cinquenta, o assalto é considerado o maior do Brasil e terceiro maior do mundo.

No dia posterior ao furto, os integrantes da quadrilha se dirigiram até uma concessionária de veículos e efetuaram compra de 11 carros no valor aproximado de um milhão de reais, pagos em espécie.

Devido as circunstâncias e o comportamento dos envolvidos na venda dos 11 veículos, que aceitaram grande montante de dinheiro em espécie sem verificação de 
DOI 10.20873/uft.2359-0106.2021.v8n2.p507-525

origem, da mesma maneira que não comunicaram às autoridades sobre a movimentação atípica, o Juiz Federal Danilo Fontenelle Sampai na ação penal de oo 2005.81.00.014586-0, em sentença, compreendeu que restou configurado o crime de lavagem de capitais sendo cabível a aplicação da Cegueira Intencional. Para o juiz os donos da empresa ignoraram o fato da elevada possibilidade de que o dinheiro usado para pagamento dos automóveis era proveniente de crime incorrendo no delito tipificado nos artigos $1^{\circ}$, V e VII, $\S 1^{\circ}$, I e $\S 2^{\circ}$ I e II, da Lei 9.613 de 1998.

Para sustentar a teoria na sentença condenatória o Magistrado considerou a existência do dolo eventual, onde o agente anteviu o possível resultado lesivo de sua conduta, porém ignorou a origem ilícita dos valores, aceitando o risco com a finalidade de ter vantagem.

Merecem destaque as construções jurisprudenciais norte-americanas relativamente ao tema. A lei norte-americana não é explícita quanto à admissão ou não do dolo eventual no crime de lavagem de dinheiro. Não obstante, por construção jurisprudencial, tal figura vem sendo admitida nos tribunais norte-americanos através da assim denominada willful blindness ou conscious avoidance doctrine, literalmente a doutrina da "cegueira deliberada" e de "evitar a consciência". As instruções dirigidas ao júri em casos da espécie são ilustrativamente denominadas de ostrich instructions, literamente "as instruções da avestruz". A idéia é a de que: "A justificação substantiva para a regra é que ignorância deliberada e conhecimento positivo são igualmente culpáveis. A justificativa textual é que, segundo o entendimento comum, alguém 'conhece' fatos mesmo quando ele está menos do que absolutamente certo sobre eles. Agir 'com conhecimento', portanto, não é necessariamente agir apenas com conhecimento positivo, mas também agir com indiferença quanto à elevada probabilidade da existência do fato em questão. Quando essa indiferença está presente, o conhecimento 'positivo' não é exigido." (...) Eu previno vocês que uma acusação de cegueira deliberada não os autoriza a concluir que o acusado agiu com conhecimento porque ele deveria saber o que estava ocorrendo quando da venda da propriedade ou que, em exercício de adivinhação, ele deveria saber o que estava ocorrendo ou porque ele foi negligente em reconhecer o que estava ocorrendo ou porque ele foi incauto ou tolo em reconhecer o que estava ocorrendo. Ao contrário, o Governo deve provar acima de qualquer dúvida razoável que o acusado motivadamente e deliberadamente evitou descobrir todos os fatos. (...) Resta incontroverso, pois, que ocorreu a venda de onze veículos por parte da Brilhe Car e com a intervenção de José Charles. Recorde-se, aqui, os conceitos de dolo eventual e a doutrina da cegueira deliberada (willful blindness ou conscious avoidance doctrine) expostos anteriormente, sendo que, pelo exposto, convenço-me que José Charles Machado de Morais sabia que a origem do

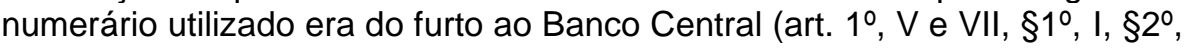
I e II da Lei 9.613/98), não sendo o caso dos irmãos José Elizomarte e Francisco Dermival que, ao que tudo indica, não possuíam tal percepção, mas certamente sabiam ser de origem ilícita. (...) Recorde-se, aqui e uma vez mais, os conceitos de dolo eventual e a doutrina da cegueira deliberada 
(willful blindness ou conscious avoidance doctrine) expostos anteriormente, no que pese entendermos que José Charles sabia da ocorrência do furto e, conseqüentemente, da origem do dinheiro, bem como as condutas dos proprietários da Brilhe Car José Elizomarte e Francisco Dermival ao não se absterem de tal negociação suspeita, nem comunicarem às autoridades responsáveis. (Poder Judiciário - Justiça Federal de primeiro grau da $5^{\mathbf{a}}$ Região - Seção Judiciária do Ceará - 11 1 Vara - Sentença prolatada em 28/06/2007 pelo Juiz Titular Danilo Fontenelle Sampaio - Processo no 0014586-40.2005.4.05.8100 (2005.81.00.014586-0).

Porém, insta mencionar que foi ignorado pelo juiz de primeira instância que na data dos fatos, o artigo $1^{\circ}, \S 2^{\circ}$, inciso I, da lei de prevenção à lavagem de dinheiro, não admitia a punição na modalidade de dolo eventual, sendo necessário que a punição se desse apenas a título de dolo direto, ou seja, era indispensável pleno conhecimento da ilicitude dos bens.

Inconformados com a sentença condenatória, os réus recorreram e em segunda instância os donos da concessionária foram absolvidos pelo Tribunal Regional Federal da 5 5 $^{a}$ Região na Apelação Criminal 5.520-CE. A sentença deliberada pelo juiz de primeira instância foi reformada em observância a redação do artigo $1^{\circ}, \S 2^{\circ}$, inciso II da Lei $9.613 / 1998$, que à época dos fatos determinava ser indispensável a existência de dolo direto para que a conduta fosse considerada como lavagem de dinheiro, sendo inamissível aplicação do dolo eventual.

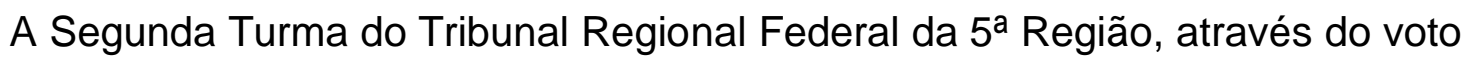
do desembargador Federal Rogério Fialho Moreira, firmou 0 seguinte posicionamento:

2.4- Imputação do crime de lavagem em face da venda, por loja estabelecida em Fortaleza, de 11 veículos, mediante o pagamento em espécie: a transposição da doutrina americana da cegueira deliberada (willful blindness), nos moldes da sentença recorrida, beira, efetivamente, a responsabilidade penal objetiva; não há elementos concretos na sentença recorrida que demonstrem que esses acusados tinham ciência de que os valores por ele recebidos eram de origem ilícita, vinculada ou não a um dos

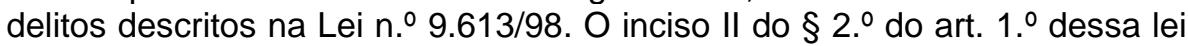
exige a ciência expressa e não, apenas, o dolo eventual. Ausência de indicação ou sequer referência a qualquer atividade enquadrável no inciso II do $\S \S 2^{\circ}$. - Não há elementos suficientes, em face do tipo de negociação usualmente realizada com veículos usados, a indicar que houvesse dolo

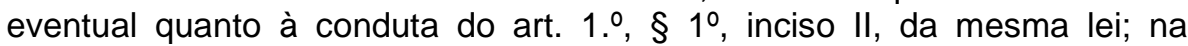
verdade, talvez, pudesse ser atribuída aos empresários a falta de maior diligência na negociação (culpa grave), mas não, dolo, pois usualmente os negócios nessa área são realizados de modo informal e com base em confiança construída nos contatos entre as partes. (BRASIL, 2008, p. 207) 
DOI 10.20873/uft.2359-0106.2021.v8n2.p507-525

Cumpre destacar que apesar do voto pela absolvição, o Relator Desembargador Federal Rogério Fialho Moreira entende ser possível a aplicação da teoria da Cegueira Deliberada no ordenamento jurídico brasileiro, quando no caso concreto o tipo penal aceita a punição a título de dolo eventual.

Entendo que a aplicação da teoria da cegueira deliberada depende da sua adequação ao ordenamento jurídico nacional. No caso concreto, pode ser perfeitamente adotada, desde que o tipo legal admita a punição a título de dolo eventual. (BRASIL, 2008, p. 207)

O advento da Lei $n^{\circ} 12.683 / 12$ trouxe mudanças na redação do artigo $1^{\circ}, \S^{\circ}$, inciso II da Lei 9.613/1998, os delitos de lavagem de dinheiro passaram a aceitar tanto o dolo direto como o dolo eventual, a partir de então tornou-se possível a aplicação da Teoria da Cegueira Deliberada em delitos de lavagem de capitais.

\subsection{A Operação Lava Jato}

A Operação Lava Jato é a investigação que deflagrou o maior esquema de corrupção já descoberto na história do Brasil. A investigação tem como alvo desmantelar um esquema bilionário de desvio de dinheiro e corrupção na Petrobras, o esquema foi orquestrado conjuntamente por políticos e doleiros brasileiros.

Segundo o site do Ministério Público Federal:

O nome do caso, "Lava Jato", decorre do uso de uma rede de postos de combustíveis e lava a jato de automóveis para movimentar recursos ilícitos pertencentes a uma das organizações criminosas inicialmente investigadas. Embora a investigação tenha avançado para outras organizações criminosas, o nome inicial se consagrou. A operação Lava Jato é a maior investigação de corrupção e lavagem de dinheiro que o Brasil já teve. Estima-se que o volume de recursos desviados dos cofres da Petrobras, maior estatal do país, esteja na casa de bilhões de reais. Soma-se a isso a expressão econômica e política dos suspeitos de participar do esquema de corrupção que envolve a companhia. (BRASIL, s/a, n.p.)

O Ministério Público Federal propôs, desde a deflagração da operação até o momento, diversas ações penais. Entre os numerosos delitos investigados os que surgem em maior grau são os crimes tipificados na Lei 9.613. Será objeto de observação do presente artigo alguns casos em que a teoria da cegueira intencional serviu como fundamento para sentença condenatória. 
DOI 10.20873/uft.2359-0106.2021.v8n2.p507-525

Nos autos da ação penal ํo 5013405-59.2016.4.04.7000 o casal de marqueteiros João Cerqueira de Santana Filho e Mônica Regina Cunha Moura foram condenados pela pratica delituosa de lavagem de dinheiro. A sentença condenatória teve como base de sustentação a teoria da Cegueira Deliberada. O Juiz Federal Sérgio Fernando Moro (2017, p. 110) fundamentou em sentença:

\begin{abstract}
A postura de não querer saber e a de não querer perguntar caracterizam ignorância deliberada e revelam a representação da elevada probabilidade de que os valores tinham origem criminosa e a vontade realizar a conduta de ocultação e dissimulação a despeito disso.

Encontram-se, portanto, presentes os elementos necessários ao reconhecimento do agir com dolo, ainda que eventual, na conduta de Mônica Regina Cunha Moura e de João Cerqueira de Santana Filho.

Segundo, tinham Mônica Regina Cunha Moura e de João Cerqueira de Santana Filho presentes os riscos concretos, de que se tratava de valores oriundos de crimes de corrupção, não só pelas circunstâncias ilícitas da transação, com adoção de expedientes sofisticados de ocultação e dissimulação, mas também pelo exemplo da Ação Penal 470. Mesmo tendo eles presentes esses riscos, persistiram na conduta delitiva, ou seja, receberam os valores, com ocultação e dissimulação. Tinha ainda condições não só de recusar o pagamento na forma feita, mas de aprofundar o seu conhecimento sobre as circunstâncias e a origem do dinheiro, tendo preferido não realizar qualquer indagação a esse respeito.
\end{abstract}

Assim sendo, o Juiz singular condenou os réus em 8 anos e quatro meses pelo crime de lavagem de dinheiro, os agentes agiram com dolo eventual na linha da teoria da Cegueira Intencional, pois apesar de plenamente possível verificar acerca da origem do dinheiro recebido, preferiram agir com ignorância deliberada com a finalidade de obter vantagem indevida.

\title{
4.3 Mensalão
}

Ação Penal $n^{\circ} 470$, conhecida como Mensalão consistiu em uma organização de esquema de propina, chefiada por ministros e deputados com a finalidade de compra de apoio político, a aludida organização começou a atuar em 2002 e somente em 2005 foi descoberta, sendo julgada pelo Supremo Tribunal Federal no ano de 2012.

Segundo consta em uns dos sites do Ministério Público Federal:

Em 2006, o procurador-geral da República narrou na denúncia que havia uma "sofisticada organização criminosa, dividida em setores de atuação, que se estruturou profissionalmente para a prática de crimes como peculato, 
DOI 10.20873/uft.2359-0106.2021.v8n2.p507-525

lavagem de dinheiro, corrupção ativa, gestão fraudulenta, além das mais diversas formas de fraude". (BRASIL, 2012, n.p).

O nome de "Mensalão" ficou marcado pelo modo que a organização criminosa funcionava, os deputados envolvidos no esquema recebiam com regularidade uma espécie de mesada, recurso financeiro desviado que garantia o apoio necessário e irrestrito ao governo.

Nas palavras de Harada (2006, p. 1):

\begin{abstract}
Literalmente, a palavra 'mensalão' significa uma grande soma de dinheiro que se paga, ou se recebe todo mês, em virtude de uma determinada obrigação. Não é nesse sentido que a mídia tem noticiado. Antecipando ao trabalho dos dicionaristas pode-se afirmar, com base naquilo que passou a ser do conhecimento público, que o 'mensalão' significa um recurso financeiro extra a ser pago, com regularidade, a determinados deputados, para agilizar a aprovação de projetos legislativos de interesse do governo, nem sempre coincidentes com o interesse público, assim entendido como o somatório dos interesses individuais dos cidadãos.
\end{abstract}

Como verificou-se os envolvidos no esquema de corrupção foram denunciados por diversos crimes, incluindo o crime de lavagem de capitais. $O$ enfretamento do Supremo sob a questão da aplicação, ou não, da teoria da Cegueira Delibera surge justamente na divergência de entendimento sobre a possibilidade de cabimento do dolo eventual nos moldes da Teoria da Evitação da Consciência no crime de lavagem de dinheiro. Assim como os demais casos citados nesse trabalho, a questão girava entorno do fato de que os réus possuíam plenas condições de averiguar que os valores recebidos eram de origem ilícita, porém optaram pela ignorância com a finalidade de auferir vantagens.

O Ministro Marco Aurélio, em seu voto, se manifestou temerário ao uso da Teoria das Instruções da Avestruz e a possibilidade do dolo eventual no crime de lavagens de capitais. Segundo ele permitir o dolo eventual nestes crimes ensejaria em prejuízo para advogados criminalistas, que poderiam vir a ser acusados de lavagem de dinheiro pelos honorários recebidos por defesa de réus acusados de tráfico de drogas por exemplo.

Assusta-me, Presidente, brandir que, no caso de lavagem de dinheiro, a ordem jurídica contenta-se com o dolo eventual. Não quero assustar os criminalistas, mas vislumbro que teremos muitas ações penais contra criminalistas, no que são contratados por 
DOI 10.20873/uft.2359-0106.2021.v8n2.p507-525

acusados de delitos até gravíssimos. É claro que poderão supor que os honorários, os valores estampados nos honorários são provenientes de crimes praticados por traficantes, por contraventores e por outros criminosos, valendo notar que houve a reforma da lei no 9613/98. Abandonou-se o rol exaustivo referente ao crime antecedente. Hoje, numerário proveniente de qualquer crime poderá ser tido como lavado ou como branqueado, vocábulo da preferência de alguns. (BRASIL, 2012, p. 31)

Apesar de não ser unânime, o voto da maioria foi no sentindo da possibilidade da aplicação do dolo eventual nos delitos de lavagem de dinheiro. Tanto a Ministra Rosa Weber, quanto o Ministro Celso de Mello sustentaram em seus votos a admissão da teoria da Cegueira Deliberada no crime de lavagem de valores.

O Ministro Celso de Mello votou com o relator (Ministro Joaquim Barbosa) no sentindo da condenação dos acusados. Em seu voto admitiu a possibilidade de configurar crime de lavagem de capitais mediante o dolo eventual, com fundamento na Teoria da Cegueira Deliberada, porém pontuou que tal teoria deve ser aplicada com cautela. Ainda explicou que, conforme essa teoria, o agente finge não perceber determinada situação de ilicitude para alcançar a vantagem pretendida (STF, 2012).

A Ministra Rosa Weber foi quem tratou da Teoria da Cegueira Intencional mais especificamente, sustentando aplicabilidade da modalidade de dolo eventual em crimes de lavagem de dinheiro no Ordenamento Jurídico Brasileiro.

Nesta ação penal, há elementos probatórios suficientes para concluir que os acusados beneficiários agiram dolosamente, se não com dolo direto, então com dolo eventual. Qualquer pessoa minimamente razoável recusaria o recebimento de valores vultosos em espécie nessas condições ou, antes de recebê-los, preocupar-se-ia, pelo menos, em aprofundar o seu conhecimento sobre a origem do dinheiro e do motivo da realização dos pagamentos naquelas circunstâncias. No presente feito, os acusados beneficiários, os parlamentares, não só escolheram prosseguir na conduta delitiva, aceitando receber o dinheiro nas condições suspeitas, e com isso participando passivamente do crime de lavagem de dinheiro, mas igualmente aderiram à conduta de maneira ativa, enviando pessoas interpostas ou utilizando mecanismos ainda mais complexos, sem, em qualquer das hipóteses, contabilizar os valores. (BRASIL, 2012, p. 1.301)

Em outro trecho do seu voto a Ministra Weber segue fundamentando que deve ser responsabilizado aquele que age com indiferença quanto a consequência 
de sua conduta, quando tinha plena capacidade de antever o resultado, aceitando a possibilidade de estar cometendo crime.

\begin{abstract}
Pode-se identificar na conduta dos acusados-beneficiários, especialmente dos parlamentares beneficiários, a postura típica daqueles que escolhem deliberadamente fechar os olhos para o que, de outra maneira, Ihes seria óbvio, ou seja, o agir com indiferença, ignorância ou cegueira deliberada.

Para o crime de lavagem de dinheiro, tem se admitido, por construção do Direito anglo-saxão, a responsabilização criminal através da assim denominada doutrina da cegueira deliberada ( willful blindness doctrine). Em termos gerais, a doutrina estabelece que age intencionalmente não só aquele cuja conduta é movida por conhecimento positivo, mas igualmente aquele que age com indiferença quanto ao resultado de sua conduta. (STF, 2012, p. 1.297)
\end{abstract}

Apesar da análise pragmática da teoria da Cegueira Deliberada pelo Supremo Tribunal Federal na ação Penal $n^{\circ} 470$, restou claro que, a despeito de não unanime, a teoria estudada é aceita pela Suprema Corte, consequentemente podendo ser recepcionada por demais Cortes e Juízos.

\title{
5 CONSIDERAÇÕES FINAIS
}

Conforme verificou-se na presente pesquisa, a Teoria da Cegueira Deliberada encontra aceitação na jurisprudência pátria, sendo aplicada em casos de relevância nacional. A aplicação da teoria com base no dolo eventual, apresenta ser uma maneira para coibir e combater crimes de lavagem de dinheiro, principalmente nos casos em que o "lavador" se utilizava de uma lacuna legislativa para o cometimento de delitos através da cegueira intencional.

A despeito da aceitação na jurisprudência, doutrinariamente, a Teoria da Evitação da Consciência não encontra aceitação unanime, sendo criticada por parcela da doutrina que vê como preocupante a possibilidade de que a negligência do agente seja punida a título de dolo eventual.

É importante ressaltar que a importação desta teoria para o ordenamento jurídico Brasileiro, demanda cuidado e reflexões para não ser utilizada de forma arbitrária. Segundo Gomes (2016) existem regras essenciais para a aplicação teoria da cegueira deliberada.

Observou-se no trabalho que a aplicação da teoria da evitação da consciência é viável no Brasil desde que seja utilizada de modo que não viole os 
princípios de legalidade e de presunção de inocência. Portanto, há limites a serem obedecidos, a cegueira deliberada não pode ser aplicada de forma deliberadamente cega (GOMES, 2016).

Para bem reforçar acerca da aplicabilidade da teoria e seus requisitos, vale a pena destacar ponto essencial do voto da Ministra Weber na Ação penal $n^{\circ} 470$ em que discorre sobre exigências para o reconhecimento do dolo eventual no caso que que o agente tenha praticado cegueira intencional:

\begin{abstract}
Exige-se, para reconhecimento do dolo eventual, cumulativamente, (i) que o agente pratique condutas de ocultação e dissimulação (também exigidas no dolo direto), (ii) que o agente, ao realizá-las, tenha ciência da elevada probabilidade de que os bens, direitos ou valores envolvidos provenham de crimes antecedentes, (iii) que 0 agente, mesmo tendo presente a probabilidade da origem criminosa, persista indiferente na conduta delitiva de ocultação ou dissimulação, deliberadamente evitando aprofundar o conhecimento acerca da origem criminosa dos bens, direitos ou valores envolvidos, a despeito de em condições de fazê-lo (STF, 2012, p. 13001301).
\end{abstract}

Por fim, ao final desta pesquisa entende-se que a Teoria da cegueira deliberada se faz presente no ordenamento jurídico Brasileiro tendo adeptos por uma parcela da doutrina podendo servir para embasar sentenças em crimes de lavagem de capitais, na busca em combater impunidades e garantir eficácia legislativa penal em casos complexos.

\title{
REFERÊNCIAS
}

BECK, Francis. A doutrina da cegueira deliberada e sua (in)aplicabilidade ao crime de lavagem de dinheiro. Revista de Estudos Criminais, São Paulo, v. 41, n. 41, p. 47-49, abr./jun. 2011.

BITENCOURT, Cezar Roberto. Tratado de direito penal: parte geral. 24. ed. Edição revista, ampliada e atualizada. São Paulo: Saraiva Educação, 2018, versão digital.

BRASIL. Ação Penal no 501340559.2016.4.04.7000/PR. Disponível em: http://s.conjur.com.br/dl/moro-condena-joao-santana-cegueira.pdf. Acesso em: 20 de setembro de 2020.

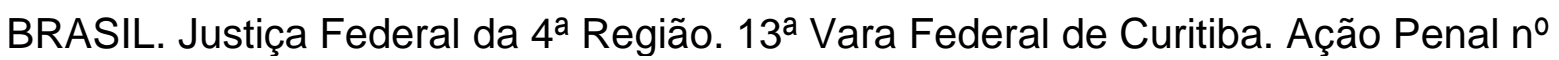
501340559.2016.4.04.7000/PR. Juiz Federal Sérgio Fernando Mouro, Curitiba, 02 fev. 2017. Disponível em: http://www.mpf.mp.br/para-o-cidadao/caso-lava- 
jato/atuacao-na-1a-instancia/denuncias-do-mpf/documentos/sentencasantana.pdf. Acesso em: 23 de setembro de 2020.

BRASIL, Ministério Público Federal, Disponível em: http://www.mpf.mp.br/grandescasos/lava-jato/entenda-o-caso. Acesso em: 24 de setembro de 2020.

BRASIL, Ministério Público Federal, Disponível em:

http://www.turminha.mpf.mp.br/honestidade/corrupcao/mensalao/entenda-o-caso/oque-foi-o-mensalao. Acesso em: 24 de setembro de 2020.

BRASIL. Supremo Tribunal Federal. Acórdão. Ação Penal no 470/MG. Rel. Joaquim Barbosa, 27 ago. 2012. Diário da Justiça Eletrônico, Brasília, 22 abr. 2013.

BRASIL, Tribunal Regional Federal da 5ª Região, Segunda Turma, Apelação Criminal 5520/CE, Desembargador Federal Rogério Fialho Moreira, Julgamento em 09 de setembro de 2008, Publicado no Diário da Justiça de 22 de outubro de 2008, p.207.

BRASIL, Tribunal Regional Federal da da 5aㅗ Região, Sentença de Ação Penal Pública $n^{\circ}$ 2005.81.00.014586-0 prolatada em 28/06/2007. Autor: Ministério Público Federal. Réu: Antônio Jussivan Alves dos Santos e outros. Juiz Federal: Danilo Fontenelle Sampaio. Fortaleza, 28 de junho de 2007. Disponível em: https://www.jfce.jus.br/consultaProcessual/resconsproc.asp. Acesso em: 17 de setembro de 2020.

CABRAL, Bruno Fontenele. Breves comentários sobre a teoria da cegueira deliberada (willful blindness doctrine). Revista Jus Navigandi, Teresina, v. 17, n. 3193, 29 mar. 2012. Disponível em: https://jus.com.br/artigos/21395. Acesso em 23 de setembro de 2020.

CALLEGARI, André Luís; WEBER, Ariel Barazzetti. Lavagem de dinheiro. 2 2a edição. São Paulo: Editora Atlas, 2017, p. 125

CARRARA, Francesco. Programa do curso de direito criminal. São Paulo: Saraiva, 2002.

CUNHA, Rogério Sanches. Manual de direito penal: parte geral (arts. 1ำ ao 120). 4.ed. Edição revista, ampliada e atualizada. Salvador: JusPODIVM, 2016.

GOMES, Luiz Flávio. Dilma, Temer, Lula, Aécio... podem ser condenados por cegueira deliberada? Em tese, sim. Caso Messi ajuda entender o assunto. Revista Jus Navigandi, ISSN 1518-4862, Teresina, ano 21, n. 4779, 1 ago. 2016. Disponível em: https://jus.com.br/artigos/51054. Acesso em 18 de setembro de 2020. 
HARADA, Kiyoshi. Mensalão e seus reflexos. Revista Jus Navigandi, ISSN 15184862, Teresina, ano 11, n. 925, 14 jan. 2006. Disponível em: https://jus.com.br/artigos/7829. Acesso em 25 de setembro de 2020.

LUBAN, David. "Contrieved Ignorance”, The German Law Journal, Toronto, 1999. p. 968. apud RAGUÉS I VALLĖS, Ramon. La ignorancia deliberada en derecho penal. Barcelona: Editora Atelier, 2007. p. 146.

MARTINS, Luiza Farias. A doutrina da cegueira deliberada na lavagem de dinheiro: aprofundamento dogmático e implicações práticas. Revista de estudos Criminais, São Paulo, v. 12, n. 55, p. 137, out./dez. 2014.

MORO, Sérgio Fernando. Crime de lavagem de dinheiro. 1. ed. São Paulo: Saraiva, 2010.

MORO, Sérgio Fernando. Sobre o elemento subjetivo no crime de lavagem. In: BALTAZAR JÚNIOR, José Paulo; MORO, Sergio Fernando (Org.). Lavagem de dinheiro: comentários à lei pelos juízes das varas especializadas em homenagem ao Ministro Gilson Dipp. Porto Alegre: Livraria do Advogado. 2007. P. 94.

PRADO, Luiz Regis. Curso de Direito Penal Brasileiro: Parte Geral - arts. 1ํa 120. 10 ${ }^{\underline{a}}$ ed. São Paulo: Revista dos Tribunais, 2011.

ROBBINS, Ira P. The Ostrich Instruction: Deliberate Ignorance as a Criminal Mens Rea. The Journal of Criminal Law and Criminology, n. 81, (1990), p.196.

ROXIN, Claus. La Teoria del Delito en la Discusión Actual. Lima: Grijley, 2007.

SANTOS, Juarez Cirino dos. A moderna teoria do fato punível. $4^{a}$ ed. Curitiba: ICPC, Lumen Juris, 2005.

TELES, Ney Moura. Direito Penal: parte geral: arts. 1a a 120, volume 1. 2.ed. São Paulo: Atlas, 2006.

VALLES, Ramon Ragus. La Ignorância Deliberada en Derecho Penal. Barcelona: Atelier, 2007, p. 65.

WELZEL, Hans. Derecho Penal alemán. Santiago: Ed. Jurídica de Chile, 1970. p.277. apud. 